\title{
"GUNN'S DOTS"
}

\section{To the Editor of THE BRITISH JouRnal of OpHTHALMOLOGY}

SIR,-Your annotation on the subject of "Gunn's dots" in the February number of the Journal seems to me to deny by implication any clinical significance to these dots. As an old clinical assistant of Marcus Gunn, I feel that this should not be allowed to pass without comment. First, it is quite obvious, not only from the false descriptions in text-books, but also from what I have heard in conversation, that many ophthalmic surgeons have never seen these dots. The main reason for this is probably that they have never learned how to look for them. The ophthalmoscope mirror used must be a small plain one and the source of illumination should be a solid flame. Marcus Gunn himself was in the habit of using an Argand burner for the purpose. Most of us, unfortunately, have only electric light in our dark rooms, but one can get a near approximation to a solid flame by turning the grid nearly edgeways on and using the clear glass. By this means one gets a fair approximation to a small solid illuminated area on the retina. The dots can then be seen in appropriate cases as small sparkling spots shining out for a moment just where the dark and light areas meet. They usually show up most clearly, in my experience, below or above the disc close to the vessels, or in the area lying between the main branches above and below. Sometimes they can be seen actually on the surface of the larger vessels.

In questions which depend solely on clinical observations, it is a matter of great difficulty to adduce convincing proofs of the connection between symptoms and signs. The weight we attach to any sign as cause of a symptom must depend on the frequency of the association of the sign with the symptom. I do not for a moment suggest that all cases of intolerance of glare will show Gunn's dots, but I must say that in my own experience I have found these present in a very large number of cases where the principal complaint has been intolerance of glare, and especially so in cases where there has been little or no error of refraction to account for symptoms of eye-strain. In support of my contention, I may be pardoned for citing a case in which I had omitted to note their presence. One August, during Mr. Gunn's absence from town, I was looking after his practice, and a small boy was brought to see me from the seaside. The history was that every summer at the seaside he got headaches and slight attacks of conjunctivitis, and the local doctor had suggested that there must be an error of refraction. I tested the boy carefully under atropin, and found only a very small degree of simple hypermetropia, and I assured the 
parents that the boy's eyes were excellent, and that I could not ascribe the symptoms to the small error that I found. Rightly enough; they were not satisfied with my opinion, and Mr. Gunn saw the boy on his return to town. He noted the presence of Crick dots, which I had failed to see because I had failed to look for them, and the protection of the boy's eyes by tinted glasses completely relieved the symptoms. Hardly a summer has passed since then without producing a case almost exactly analogous. As Marcus Gunn always taught, these cases seem to be much more affected by glare reflected from a bright surface, i.e., the sea or sand, or white chalk roads, than by direct light.

Yours, etc.,

Leslie Paton.

P.S.-One cause for the difficulty many surgeons have in seeing these dots, is the fact that the majority of ophthalmoscopes are made without the small plane mirror.

February 13, 1918.

\section{BOOK NOTICES}

Transactions of the Ophthalmological Society of the United Kingdom. Vol. XXXVII. London: J. AND A. CHURCHILL, 7, Great Marlborough Street. Price 12s. 6d. net. 1917.

The thirty-seventh volume of the Transactions contains the proceedings of the Society during the Congress held in May, 1917.

This volume, which is well illustrated, maintains the high standard that the Transactions has led us to expect. It includes the presidential address by Mr. E. Treacher Collins, the Bowman Lecture on "Colour-sense phenomena and some inferences which they seem to suggest" by Sir George A. Berry, and discussions on "Concussion injuries of the visual apparatus" and "The employment of the Blind," not to mention cases and papers of interest to ophthalmic surgeons. These will be noticed in due course in our columns.

Ophthalmological Society of Egypt. Bulletin of I917. Printed by M. Roditi and Co.

This volume (illustrated) of 108 pages comprises the proceedings of the fourteenth annual meeting of the Ophthalmological Society of 